\title{
How Adolescent Students with Disabilities and / or Complex Needs Perceive the Notion of Resilience: A Study in Greece and England
}

\author{
Maria Georgiadi and Stefanos Plexousakis \\ University of Crete, Greece \\ https://orcid.org/0000-0002-6846-0156 \\ https://orcid.org/0000-0002-8463-1365 \\ Maitland Josie \\ University of Brighton, England \\ https://orcid.org/0000-0001-7932-6465 \\ Elias Kourkoutas \\ University of Crete, Greece \\ https://orcid.org/0000-0003-1346-5344 \\ Angie Hart \\ University of Brighton, England \\ https://orcid.org/0000-0002-5034-5950
}

\begin{abstract}
Adolescents with behavioral and learning difficulties are at increased risk in relation to psychological and social well-being. This study aimed to investigate the views and experiences of adolescent students, diagnosed with a variety of complex needs such as behavioral, emotional and learning difficulties, to explore potential risk and protective factors that they perceive can enable or constrain resilience. Participants in the study were adolescents both from the UK $(n=12)$ and Greece $(n=14)$, all of whom were receiving additional learning and psychological support in their school settings. A qualitative research design employed the 'draw and write' technique in addition to face-toface semi-structured interviews. Data analysis identified the protective and risk factors that adolescents associated with resilience. Two distinct categories of protective factors emerged from the data: a) personal (positive thoughts, nutrition and achievements) and b) socio-ecological factors (significant others, activities, pets, places). Risk factors were also divided into two categories: a) personal (negative thoughts and feelings and health problems) and b) socio-ecological factors (relational problems). Findings highlight the complex interplay between personal and socio-ecological factors in building resilience in adolescents who are at increased risk in relation to psychological and social well-being.
\end{abstract}


Keywords. Resilience; adolescence; complex needs; adversities; risk/ protective factors

\section{Introduction}

Defining resilience is far from straight forward (Olsson et al., 2015). Since the emergence of the construct, researchers have contributed to multiple re-workings of the concept of resilience (O'Dougherty et al., 2013). Critique of the concept has focused on the ambiguity of the terminology and instability of the construct, due to the degree of heterogeneity of responses to identified risk and protective factors (Cameron et al., 2019; Lather, Ciccheti \& Becker, 2007).

The flowchart (Figure 1) summarizes key developments in the field of resilience research and supports discussion on how the proposed research expands the current literature. Early identification of the phenomenon of positive adaptation in the face of adversity was highlighted by researchers in the 1970s. Studies in the field of health sciences discovered that some children, who were deemed to be 'at risk' from developing psychopathology, functioned unexpectedly well considering the perceived odds stacked against them.

This 'first wave' of resilience research could be seen as a response to dominant 'deficit' biomedical models of the time that sought an accurate understanding of pathology as opposed to how 'problems were averted, resolved or transcended' (O'Dougherty et al., 2013).

As the second wave of research emerged, the focus shifted to the role of strengths and protective factors in fostering resilience, leading to a developmental 'strength-based' approach, which, in schools, centered on increasing self-esteem, and the development of pastoral support systems such as school counselling (Akos \& Galassi, 2008), focus groups and peer mentoring.

As the existing literature highlights, a range of 'protective factors' are thought to 'alter responses to adverse events so that potential negative outcomes can be avoided' (Zolkoski \& Bullock, 2012, p. 2298) and significance is given to socioecological influences on the child rather than purely the biological predeterminants.

Subsequent waves of resilience research therefore moved beyond the attributes of the individual to consider the impact that the social and cultural context can have on resilience; it apportioned responsibility between parents, carers, schools, communities and other organizations that influence the child as opposed to merely 'responsibilising' the individual who is facing disadvantage (Hart et al., 2016). Lerner et al. (2013) refer to resilience within a paradigm of relational developmental systems theory. That is to say, they conceptualize resilience as a dynamic construct that responds to ecological factors and, as such, is malleable over time and context. Through this interpretation, resilience can be regarded as emerging from a kind of 'ordinary magic' (Masten, 2018), through which a combination of protective mechanisms can result in an extraordinary adaptive quality that buffers against adversity to defy the odds stacked against some children. 
Multiple studies trialed projects which aimed to capitalize on 'critical turning points' including the transition from primary to secondary education, adolescence, and school completion. These key phases are considered vital opportunities to foster 'systems of influence' (Masten \& Obradović, 2008; Riley \& Masten, 2005) around the individual that might negate early life adversity and promote long-term well-being. By increasing opportunities for competence and developing positive and meaningful relationships, contextual protective factors are thought to foster personal growth in spite of adversity (Luthar, 2006).

This important shift away from the earlier focus on individual characteristics, placed significant focus on acknowledging the dynamic interplay between elements of the microsystem made up of peer, family and school relationships and wider contextual influences such as social, cultural and political factors. Existing resilience literature provides powerful support for the potential of schools to drastically improve the outcomes of people within the system, in spite of adverse conditions (Lerner et al., 2013). Understanding the complexities of the dynamic matrix of systemic influences enables schools and those involved in supporting children and young people to carefully consider how conditions of adversity and disadvantage can be reinforced or negated by the system they are a part of. Being more explicit about the environmental aspects influencing resilience has been the focus of contemporary applied resilience researchers in the field (e.g. Hart, Blincow \& Thomas, 2007), both in terms of developing strategies and resources that can be used by parents, carers and practitioners to make practical interventions and in terms of empowering young people to make 'resilient moves'.

To this end, Hart, Blincow \& Thomas (2007) have built on theoretical discourse and synthesized existing measurement tools to produce the Resilience Framework (Figure 2). This comprises five conceptual areas (basics, belonging, learning, coping and core self) and each of these suggests approaches for practitioners to help them to improve the resilience of children and young people.

Basic, Belonging and Learning are related to strategies and practices for working directly with children but also involve practitioners strategically linking with and reaching out to others. Coping and core self interventions consist of a set of microtherapeutic approaches designed for direct work with individuals which is a distinct feature between them. While Core self focuses on working at a deep intrapersonal level, Coping provides children with strategies to manage better at a specific time rather than waiting for some deeper personal transformation to occur. The framework draws together existing resilience literature and lived experience of supporting children considered 'at risk', and it was developed with school, social care and health practitioners, alongside parents, carers and young people. The Resilience Framework is underpinned by 'noble truths' of accepting, conserving, commitment and enlisting and it adopts a strengths-based approach reflecting key theories from positive psychology (Seligman \& Csikszentmihalyi, 2014). It echoes core tenets of psychological developmental theory including Deci and Ryan's Self Determination Theory (1985) and co-regulation theory (Moreno, Sanabria \& López, 2016). 


\begin{tabular}{|c|c|c|c|c|c|}
\hline \multicolumn{6}{|c|}{ Resilience Framework (Children \& Young People) Oct 2012 - adapted from Hart \& Blincow with Thomas 2007} \\
\hline & BASICS & BELONGING & LEARNING & COPING & CORE SELF \\
\hline \multirow{14}{*}{ 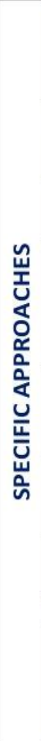 } & \multirow{2}{*}{ Good enough housing } & $\begin{array}{l}\text { Find somewhere for the child/YP to } \\
\text { belong }\end{array}$ & \multirow{2}{*}{$\begin{array}{l}\text { Make school/college life } \\
\text { work as well as possible }\end{array}$} & \multirow{2}{*}{$\begin{array}{l}\text { Understanding boundaries } \\
\text { and keeping within them }\end{array}$} & \multirow{2}{*}{ Instil a sense of hope } \\
\hline & & $\begin{array}{l}\text { Help child/NP understand their place in } \\
\text { the world }\end{array}$ & & & \\
\hline & Enough money to live & Tap into good influences & \multirow{2}{*}{$\begin{array}{l}\text { Engage mentors for } \\
\text { children/YP }\end{array}$} & Being brave & \multirow{2}{*}{$\begin{array}{l}\text { Support the child/YP to } \\
\text { understand other people's } \\
\text { feelings }\end{array}$} \\
\hline & Being safe & Keep relationships going & & Solving problems & \\
\hline & \multirow[b]{2}{*}{ Access \& transport } & The more healthy relationships the better & \multirow{2}{*}{$\begin{array}{l}\text { Map out career or life } \\
\text { plan }\end{array}$} & $\begin{array}{l}\text { Putting on rose-tinted } \\
\text { glasses }\end{array}$ & \multirow{2}{*}{$\begin{array}{c}\text { Help the child/YP to know } \\
\text { her/himself }\end{array}$} \\
\hline & & $\begin{array}{l}\text { Take what you can from relationships } \\
\text { where there is some hope }\end{array}$ & & Fostering their interests & \\
\hline & \multirow[t]{2}{*}{ Healthy diet } & $\begin{array}{l}\text { Get together people the child/YP can } \\
\text { count on }\end{array}$ & \multirow{2}{*}{$\begin{array}{l}\text { Help the child/YP to } \\
\text { organise her/himself }\end{array}$} & & \multirow{2}{*}{$\begin{array}{l}\text { Help the child/YY take } \\
\text { responsibility for } \\
\text { her/himself }\end{array}$} \\
\hline & & Responsibilities \& obligations & & soothing & \\
\hline & Exercise and fresh air & Focus on good times and places & \multirow{3}{*}{ Highlight achievements } & Remember tomorrow is & \multirow{3}{*}{ Foster their talents } \\
\hline & & Make sense of where child/YP has come & & another day & \\
\hline & Enough sleep & from & & \multirow{3}{*}{$\begin{array}{l}\text { Lean on others when } \\
\text { necessary }\end{array}$} & \\
\hline & Play \& leisure & Predict a good experience of someone or & \multirow{3}{*}{ Develop life skills } & & \multirow{3}{*}{$\begin{array}{l}\text { There are tried and tested } \\
\text { treatments for specific } \\
\text { problems, use them }\end{array}$} \\
\hline & \multirow{2}{*}{$\begin{array}{l}\text { Being free } \\
\text { from } \\
\text { prejudice \& } \\
\text { discrimination }\end{array}$} & something new & & & \\
\hline & & $\begin{array}{l}\text { Make friends and mix with other } \\
\text { children/YPs }\end{array}$ & & Have a laugh & \\
\hline \multicolumn{6}{|c|}{ NOBLE TRUTHS } \\
\hline & ACCEPTING & CONSERVING & COMMITN & AENT & ENLISTING \\
\hline
\end{tabular}

Figure 2. Resilience Framework. From Resilient therapy: working with children and families, by Hart, Blincow \& Thomas (2007). Copyright $(\odot 2007$ by the authors. Reprinted with permission.

Importantly, the Resilience Framework acknowledges the impact wider systems can have in negating risk factors and promoting resilience, for example addressing the universal need to feel safe, have access to good nutrition, outdoor exercise, good enough housing, enough sleep and positive relationships with supportive adults. Clearly unequal access to such protective factors may further disadvantage some children and young people, compounding risks posed by additional behavioral or learning needs; this clearly indicates the relationship between resilience and social justice (Hart et al., 2016). This research has responded to earlier critique of the dangers of utilising 'resilience' as a 'vehicle for the responsibilisation of individuals in place of social structures and governing institutions' (Hart et al., 2016) and is particularly relevant in relation to the increasing accountability of teachers and the raised expectation of academic rigor that does not always account for the complexity of contextual disadvantage.

\subsection{Promotion of school-based resilience}

Whilst enormous leaps have been made in resilience-related research, there is a need to consider how to situate these ideas explicitly in an academic context and ensure that school policy adequately reflects current understanding. In the UK, policies like Every Child Matters (DFE, 2003), Future in Mind (2012) and, more recently, the jointly authored 'Transforming children and young peoples' mental health provision' Green Paper (DHSC \& DfE, 2017) represent progress in the extent to which policy co-ordinates health and education service provision to reduce risks and intervene early to promote resilience. In Greece, Law 3699/2008 
indicates that services are working together to consider collective responsibility to 'reduce risk and maximize opportunities' for every child, irrespective of background or disadvantage.

In 2016, Hart et al. (2016) proposed the Boingboing framework of resilience research that seeks to interrogate the relationship between personal well-being and social equity, building on work by Prilleltensky and Prilleltensky, (2006). Overcoming adversity is aligned with a desire and actions to change in some way the conditions that have led to adversity; it exposes the impact of inequalities as a priority and acts to increase control over personal outcomes by challenging culturally imposed conditions of adversity. This approach is particularly relevant for the school community in the current climate of perceived lack of teacher autonomy and limited participation of both school staff and students in policy formation. In addition, seeking to close the attainment gap between disadvantaged students and their peers is a continuing policy priority both in Greece and the UK.

The potential of school communities to foster resilience has led to the proposition of the concept of 'Academic Resilience' (Hart \& Williams, 2015), which has been defined as 'students achieving good educational outcomes despite adversity' (What is Academic Resilience: Young Minds, 2015).

Existing school-based resilience-building interventions tend to be costly for schools, and often involve external practitioners delivering a time-limited programme that may only have a limited impact in the local context, especially after support is withdrawn (Mcpherson et al., , 2016). To this end, the Academic Resilience Approach (ARA) has been developed as a whole-school approach to improving outcomes for the most disadvantaged students, by promoting resilience throughout the school system (Hart \& Williams, 2015).

Hart and Williams (2015) propose that in order to promote academic resilience most effectively, schools require evidence-based methods of early intervention to support children at risk of underachieving academically or experiencing mental or emotional difficulties. Although aspects of the Resilience Framework (such as secure attachment relationships) have been shown to negate the impact of adverse conditions for children from high-risk backgrounds who face constellated disadvantage (Hart, Blincow \& Thomas, 2007), taking a resilient perspective as a whole-school approach is fundamental to achieving a sustainable positive impact. The ARA provides free online resources globally that support schools to develop a locally meaningful whole-school approach including: audit and planning materials and practical strategies that foster resilience across the school community, aiming to have a positive impact especially for children and young people facing adversity.

\subsection{Fostering resilience in 'at-risk' children and adolescents}

It is known that children and adolescents who face difficult psychosocial conditions are at increased risk given the associated adverse physical and psychosocial circumstances which can potentially affect their well-being and outcomes at cognitive, mental, emotional and behavioral levels (Smith, Foley \& Chaney, 2008). It is well-established that the presence of psychosocial difficulties can be interrelated with the existence of a diagnosed disability (Theron, 2016). 
Therefore, it appears that children living in adverse psychosocial conditions may be at risk of further psychological, emotional, and social/behavioral difficulties which could have a concentrated negative impact, destabilising their otherwise typical developmental trajectories (Smith et al., 2008).

In her research, Theron (2016) uses mixed methods to explore the voices of 181 marginalised rural black South African adolescents about what gives them positive adjustment in their daily lives. The research aims to identify the supportive processes which are thought to facilitate positive adjustment to disadvantaged life-worlds and how contextual and cultural realities shape such processes. The findings mention the importance of both socio-ecological and contextual factors, including the importance of women as significant figures for promoting resilience due to the absence of men. The relational importance of educational and social services provided is also highlighted; this is also identified by other studies in different cultural contexts. In their research with 28 Sesothospeaking adolescent girls from the Free State Province of South Africa, Jefferis \& Theron (2017) aimed to explore the views of adolescent girls on how teachers facilitate their resilience. According to their findings, characteristics such us providing guidance and active listening helped these girls to think positively about their futures. Li et al. (2018) interviewed 11 Chinese adolescents facing contextual adversity in order to capture their understanding of pathways leading to resilience. Their findings identify the social environment (such as school and family) alongside positive life goals and self-confidence as attributes of resilient Chinese female adolescents.

According to a qualitative study focusing on how orphaned children from parents with HIV/AIDS in South Africa (Ogina, 2012) perceive the notion of resilience, the emerging themes included risk factors such as isolation and stigma and protective factors such as positive relationships, personal assets and environmental resources.

\subsection{Fostering resilience in children and adolescents with complex needs}

There are relatively few studies with a specific focus on how resilience is fostered in children/adolescents with disabilities (Abelev, 2009; Yoshikawa et al., 2012). Furthermore, very little is known about how children and adolescents with disabilities themselves perceive the notion of resilience or the factors that they consider to be involved in building resilience. They are often left out of research because involving them can present extra methodological challenges for researchers. Furthermore, their individual characteristics are not always easy to aggregate into large data sets which will result in what are seen by researchers as prestigious publications (Hart et al., 2015). Disability is itself a complex and contested term, but in this paper, 'disabilities' refers to a known need for additional support which a child or young person is receiving through specialised educational services. These needs encompass social and communication difficulties including those experienced by young people with an autism spectrum condition, emotional and behavioral difficulties, and cognitive learning disabilities.

Harðardóttir, Júlíusdóttir \& Guðmundsson's research (2015) explored how secondary school students with learning difficulties understand resilience. The 
authors interviewed ten students with learning difficulties in order to capture their experiences of school settings and identify the helpful factors or obstacles in their learning progress. The main themes that emerged were: the difficulty these students experienced in understanding problems they faced, the stigma of labeling, and the importance of support from others (including teachers and friends) as a resilience-building mechanism.

Lyons and Roulstone (2018a) aimed to articulate children's narratives about the potential risk factors to well-being for children with speech and language disorders. The eleven participants identified potential risk factors associated with communication difficulties and academic achievement and suggested that hope, positive relationships and agency were important protective factors for their wellbeing.

The current research has focused on how adolescents who have been diagnosed as having complex needs, behavioral, emotional, developmental and learning difficulties, conceptualise resilience and identify personal and socio-ecological factors that can be considered as either risk or protective factors for building resilience essential for long term well-being. Emergent research also calls for greater emphasis on challenging the conditions of adversity by increasing the participation of marginalised groups as a way of overcoming disadvantage and contributing to social change. As Ungar (2005, p. 441) indicates, 'we would do better helping children if we spent more time asking them to tell us what they need'. To this end, the purpose of the present study is to identify young peoples' perceptions of risk and protective factors using the 'Draw and Write' technique and semi-structured interviews, with the aim of making a valuable contribution to the literature and making recommendations to inform special education professionals, parents, carers and other practitioners regarding effective support for this specific population.

It is crucial to address the fact that in many studies, the focus is on parents', teachers' and professionals' views of children's experiences, rather than the direct experiences of the child or young person. Understanding the concerns, ideas, beliefs and metaphors of children through their drawings and dialogue is important because it may be a vehicle for improving our adult understanding of their world. Consequently, this could help in the formation of support strategies in order to improve the mental health and well-being of these children (Pridmore \& Bendelow, 1995;Patrick \& Wyckoff, 2018). It is crucial to hear the voices of adolescents with special educational needs/disabilities in order to understand their perspectives in terms of decision-making and intervention programmes that are focused on them (Jönsson 2018; Palikara et al., 2018).

\section{Method}

This study employed a qualitative, narrative approach to collect the perceptions of adolescents with additional behavioral or learning needs. The qualitative case study design was employed to enable the researcher to interact with the adolescents, in order to explore their lived experiences and personal reflections on the concept of resilience (Petty et al., 2012).

In this qualitative study the 'Draw and Write' technique was employed in combination with semi-structured interviews (Pridmore \& Bendelow, 1995), as a 
way of gaining insight into children's understanding of the concept of resilience (see Appendix 1). Traditionally, children's drawings have been used in clinical settings for diagnosis and therapeutic purposes (Pridmore \& Bendelow, 1995). The 'Draw and Write' technique is an exploratory method that has been used by several researchers in the field of health psychology and education (Campbell et al., 2010; Farmer \& Porcellato 2016; Khair, Meerabeau \& Gibson 2015).

Undertaking research with children and adolescents with a variety of disabilities can sometimes be challenging. These children and young people may face difficulties relating to their literacy, cognitive understanding of what is being asked, or communication difficulties that inhibit their responses. Creative or visual data collection gives children the opportunity to explain, in their own words, the meanings of their views, enabling the researcher to understand them (Ogina, 2012). According to Pridmore \& Bendelow (1995, p. 473) 'this technique inverts the more traditional top-down methodology to a bottom-up approach and has the potential to enable all children [as long as they are at least able to draw] to participate'. This technique lends itself well to being adapted for different cultural contexts and for children with a range of additional needs.

\subsection{Participants}

The study was conducted in Greece and England. The participants in this study were 12 adolescents from one UK school and 14 adolescents from one Greek school. The participants were attending sessions with psychologists and had been diagnosed with a variety of complex needs including: Social, Emotional, and Behavioral Difficulties (SEBD); Speech, Language and Communication Needs (SLCN); Autism Spectrum Disorder (ASD); Attention Deficit Hyperactivity Disorder (ADHD) and Oppositional Defiant Disorder (ODD). The average age of the participants was 13 years and 8 months. IN total, 21 boys and 5 girls took part. The two researchers (one from Greece and one from England) were known to the participants as existing members of staff who had been working with them prior to the research. A safe, secure environment and confidentiality (subject to any safeguarding concerns) were established by the researchers, which helped the children to cooperate and feel free to express themselves to people with whom they were familiar. Regarding any concerns for participants' well-being, researchers worked with school leaders, safeguarding leads and existing therapeutic and psychological support services to ensure that appropriate follow up could be made where necessary.

\subsection{Procedure}

University research ethical permission was sought for the study as part of a wider study applying resilience-based practices. Parents/carers signed a letter of consent for their child to participate in the study. The study was then explained to young people who were asked if they wished to take part ; they were informed that they could choose not to take part or withdraw whenever they wanted to and for any reason. The adolescents were guided through the schedule of the activity and were asked to express any difficulty in understanding the task questions or what was expected of them. The researchers explained to the participants that their role was to share their perceptions as accurately as possible and help to better 
explain how young people similar to them might understand and experience resilience.

As soon as the children had completed the activity, they handed in their responses to the researcher. To relieve any possible anxiety which may have emerged from thinking about and discussing 'sensitive' material, an informal conversation was facilitated in order to alleviate possible stress, provide reassurance and determine the need for any subsequent support. Children were able to discuss and reflect on their drawings and answers in a warm and trusting atmosphere, which also helped the researchers to gain a deeper understanding of their responses and ensure accurate interpretation, by checking with participants on their own intentions.

The participants received a blank A4 paper, pencil, eraser and colours. The instructions to the participants were: 'Draw a person like yourself. It doesn't matter how well you draw, that is not important. What does this person think about their life in the future? When this person that you draw face difficulties in life, what helps them overcome these difficulties? What helps them to find courage in life? Write as much as you want in the space provided, explaining your drawing. If you have a difficulty in writing I can write for you'. The process lasted approximately 45 minutes. The researchers used the drawings and the comments they wrote on their drawings to facilitate interviews and clarify in depth what the participants meant. The follow-up questions included: 'What is your drawing about?' 'Who is that?' and 'What do you mean by saying this...'

\subsection{Data Analysis}

The collected data were obtained from children's and adolescents' drawings and narratives, followed by individual interviews (Jefferis \& Theron, 2017; Kim, 2016; Søderberg, 2006). Categories and themes were identified in a process of open coding, along with the demographics of the total sample including gender, background, and known difficulties of each child.

The data analysis procedure was based on the 'three $\mathrm{Cs}^{\prime}$ proposed by Lichtman (2006, p. 168): 'from coding to categorizing to concepts'. Analysis therefore facilitated the identification of core categories, emerging patterns and themes in three key stages. After the initial open coding, and a secondary revision in order to collapse or combine the codes, an initial list of categories was developed, which was refined again based on additional re-reading of the data to include subcategories. Lastly, the categories and subcategories were translated into themes. Throughout the data analysis process, researchers were guided by both the drawings and participants' own interpretations of the drawings in order to retain the intended meaning in the final emergent themes. This iterative data analysis process is illustrated in Figure 3.

While we questioned adolescents about their drawings, they were encouraged to determine the deeper meanings of their works through the 'Draw and Write' technique. This approach enabled the researchers to explore their deeper experiences and identify themes through their responses. Reliability was ensured by using an oral data eliciting method based on the information provided by the adolescents regarding their drawings. By decoding the data and the emerging 
themes with constant reflection on these explanations, it was possible to check for accuracy and clarify comments related to participants' drawings. To increase the depth and accuracy of collected data, the researcher triangulated information from the drawings, narratives and interviews of the adolescents.

A verification procedure was applied in order to improve the reliability (Creswell, 2014), accuracy of interpretation and credibility of the findings. To verify the findings, the researchers undertook several procedures including: (1) using a peer code to document themes and quotes in the data; (2) conducting multiple meetings with emerging opportunities to review researcher bias and develop protocols before beginning data collection; and (3) developing a modified member checking process that allowed for an external audit of themes within the data.

The researchers also developed a shared protocol for the interview process to assure uniformity in the interviews in order to allow for a review of any subconscious bias related to working with adolescents who had disabilities or had experienced adversities. The transcripts from the interviews were decoded verbatim in order to avoid any bias in terms of what adolescents reported in their drawings (Campbell et al., 2010; Khair, Meerabeau \& Gibson, 2015 ; Kuhn, 2003; Dasarraju et al., 2016; Farmer \& Porcellato, 2016).

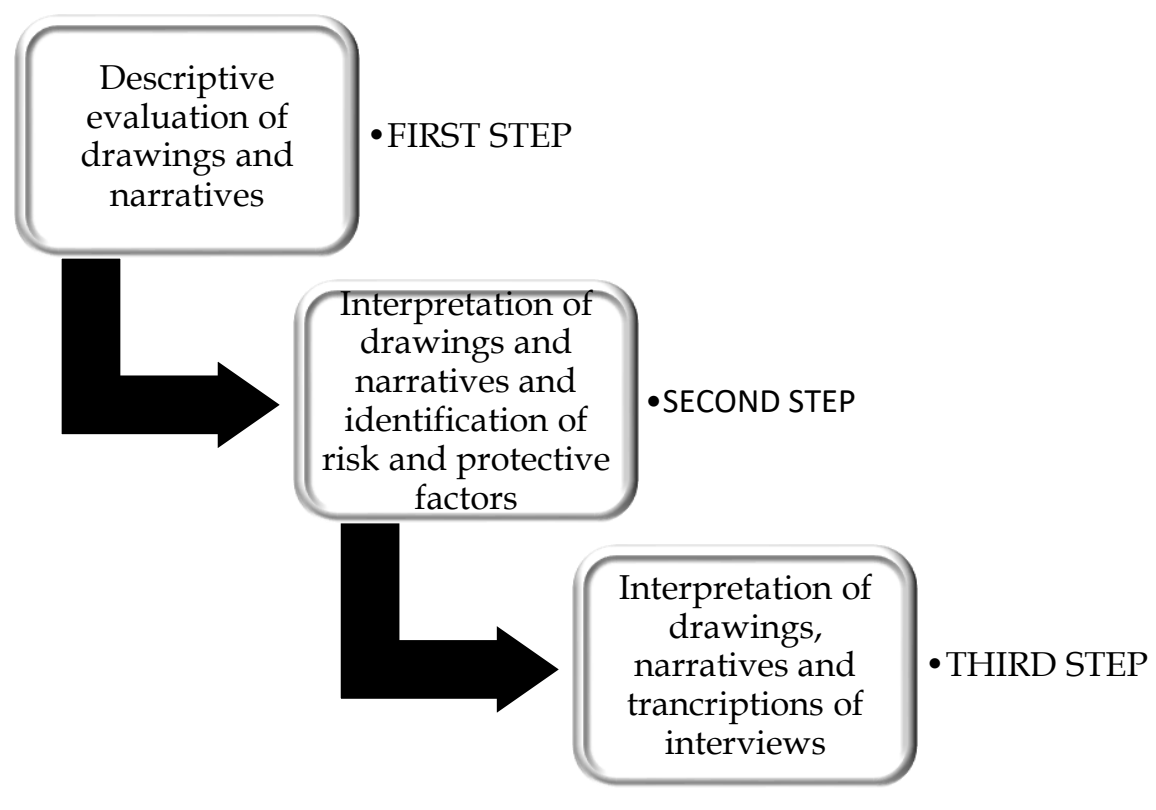

Figure 3. Procedure of analysis of research data

\section{Results}

Two main categories emerged from the data: risk factors and protective factors. Sub-categories of these themes were personal and socio-ecological factors, as illustrated in Figure 4. 


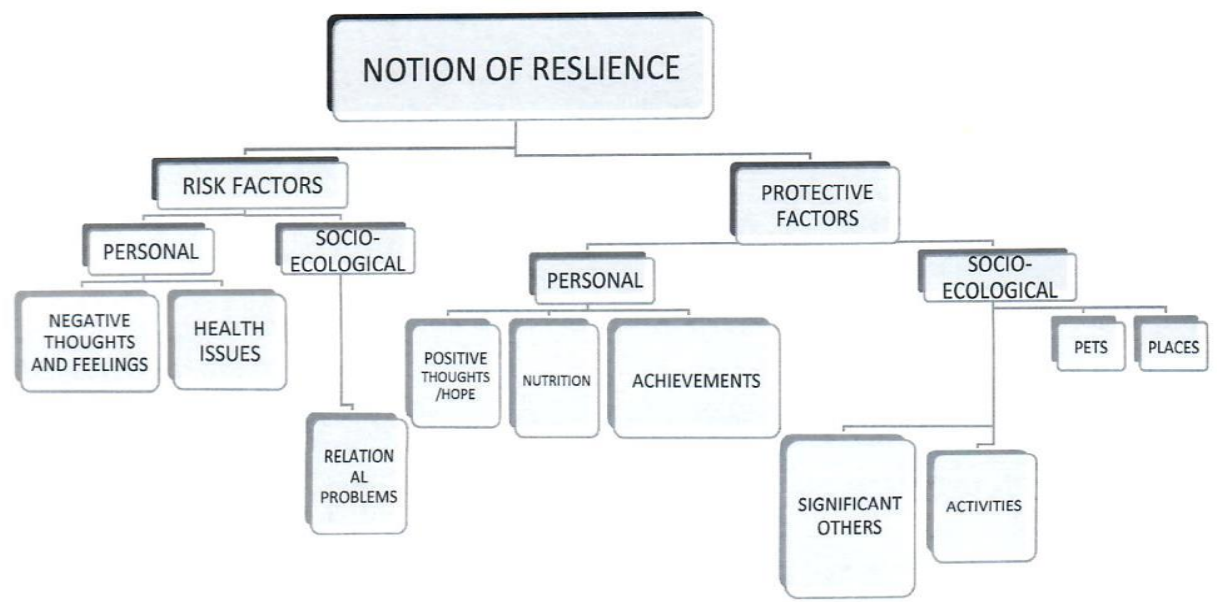

Figure 4. Themes identified from the analysis

In both the drawings and interviews, participants described situations and activities that they valued and perceived as protective factors at a personal level. These included: i) positive thoughts; ii) nutrition; iii) achievements. Protective factors at a socio-ecological level were perceived as: i) people (significant others); ii) play and activities; iii) pets; and iv) places.

In the drawings and interviews, adolescents described the following risk factors and difficulties at a personal level: i) negative thoughts and feelings (fear and low self-esteem); and ii) health problems. Two risk factors at a social-ecological level were identified as difficulties with: i) family; and ii) peers.

\subsection{Protective Factors}

\section{a) Personal factors}

Positive thoughts and hope were identified as personal protective factors by six adolescents (two from England and four from Greece). Participant 15 stated:

'I feel like my optimism tank is refilling and I find my own good life and

I have new dreams and new goals in life. I want to live!!!'

Participant 16 reported many positive thoughts and feelings that facilitated his optimism. For example:

'People love you! Don't give up! My passions are not weaknesses! Do not stop believing! My wounds make me a better person! My past does not represent me! You have a role in life, nothing is impossible!'

(see Figure 5).

Nutrition was mentioned by one participant from Greece (Participant 22; he described how good and healthy food helps him keep calm.

Achievements were mentioned by two participants (one from Greece and one from England). For example, Participant 19 stated: 'I am very proud because I managed to win a gold medal in water polo.' 
b) Socio-ecological factors

People (significant others) were mentioned by 11 adolescents (five from England and six from Greece). Participant 13 reported:

'The thing that gives me strength in life is a hug from those I love, like my girlfriend, and that empowerment makes me believe that I can succeed in life. Deep inside I know I can do it but I am afraid to believe it.'

Participant 14 mentioned: 'my parents help me to be strong and powerful and to have everything I need.'

Participant 26 reported 'my mother always helps me with homework so I can overcome any difficulties and I feel very happy.'

Play and activities were mentioned by eight participants (three from England and five from Greece). They reported watching TV and doing sports.

Participant 1 explained:

'in my drawing, I've put how to deal with difficulties - with friends playing football, playing with toys (dinosaur and cowboy), sleeping and sometimes asking family or friends to support you...sometimes you can't do that if they are part of the problem.'

Participant 4 mentioned that:

'on the coping side I have said that drawing, colouring, working one-one and asking for help are ways I can concentrate. Having something to remember someone by can make saying goodbye easier.'

Participant 5 stated that play could also be a distraction from adversity: 'in my drawing I have put that you can forget about your problems for a while or play X Box to distract yourself.'

Pets were mentioned by three participants (one from England and two from Greece). Participant 18 reported that a dog could make her really happy (see Figure 6).

Participant 8 reported: 'I have drawn me with my dog. She is always with me and calms me down when I need it.'

Places were reported by seven participants (five from Greece and two from England) who mentioned playgrounds and rooms in their house as particularly safe places to be, the beach as a relaxing place, the gym as a place to release tension, and their favourite tree as a source of comfort. Participant 18 mentioned her support from family as related to her comforting favourite places, which gave her courage to fight in life. She stated: 'When I returned back in home, I like enjoying the comfort of my warm bed.'

Participant 5 mentioned 'also I go to a dark corner of my room and sit in the dark and think of my holiday', indicating that memories of favourite places could also be considered a protective factor. 


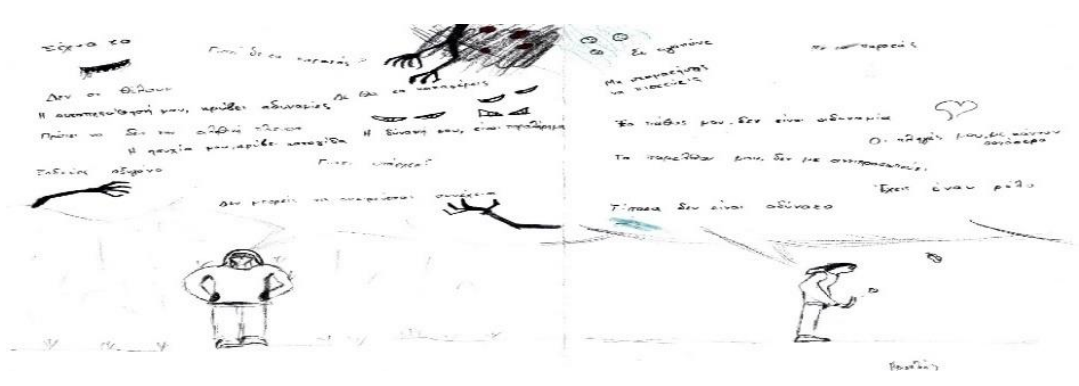

Figure 5. Drawing and accompanying words of Participant 16

Left: They don't want you! You will fail, my self-confidence hides my vulnerability. My peacefulness hides a storm. My strength is an illusion. You cannot dream all the time!

Right: They love you. Don't give it up. Don't stop believing. My passions are not weakness. My wounds make me wiser. My past does not represent me. You have a role. Nothing is impossible!

\subsection{Risk Factors}

The written answers and drawings were categorised into: a) personal and b) socioecological factors.

a) Personal factors

According to our findings, negative thoughts and feelings were mentioned by six participants in England and nine participants in Greece. Issues related to health problems were identified by two adolescents from England and one participant from Greece (see Figure 7).

Participants mentioned that negative thoughts and feelings (such as fear, low selfesteem) negatively influence their well-being and are a cause of sadness. Participants described a range of negative thoughts. For example, they reported uncertainty in relation to their performance at school, uncertainty about the future, perceived pressure from school, fear of failure and anxiety about achieving future goals related to studies.

For example, in this excerpt, Participant 15 reported feeling overwhelmed by feelings of desperation and disappointment: 'Sometimes I do feel that everything is drawn around me and I feel so lonely.'

Participant 6 stated 'when I thought about difficulties, I thought that actually, just staying alive in this world can be a struggle. Having to put up with school can be bad as well.'

Participant 7 stated: 'I can't think of how to say it or what exactly is difficult. But I have drawn killing yourself. It's a way to fix everything because then everything is over.'

Participant 13 described negative emotions as a barrier to good experiences: 'I could be feeling great, going for walks, doing activities, studying at university, socializing, be relaxed and with no worries! But something is stopping me... a fear, an anxiety, a sorrow...' 
Pressure to achieve was mentioned; for example, Participant 14, reported 'Sometimes karate makes me feel so much pressure and makes my life difficult.'

Participant 4 explained: 'on the difficulty side I have drawn a clown, who is a funny sort of joker type. It is a female clown with a beard. She finds it hard to say goodbye to someone she knew really well. Also, she finds it hard to concentrate.' (see Figure 8).

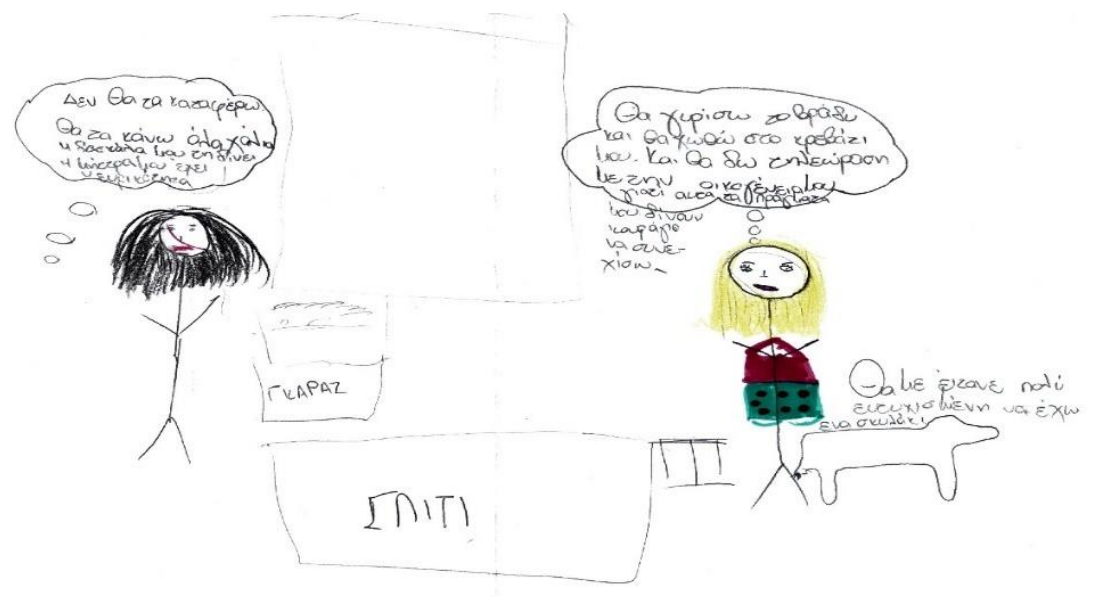

Figure 6. Drawing and accompanying words of Participant 18

Left: I will not manage it. I will mess it all up! My teacher gives on my

Nerves. My mother is Nervous all the time.

Right: When I return back Home I go into my bed and I will watch television with my Family so I take courage to carry on in life. If I had a dog, I would be very happy.
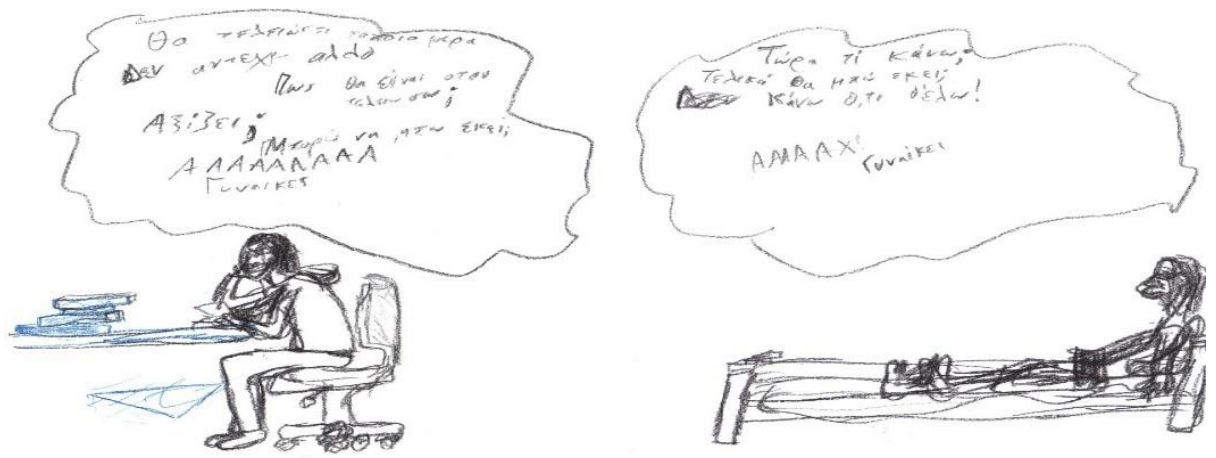

Figure 7. Drawing and accompanying words of Participant 7

Left: One day, all will be over. I can't stand it any more! How thing will be when I will be finished? Is it worth it? Can I manage to succeed to the University? Women...

Right: What am i doing now? Will i be succeeding going to the University finally? I can do whatever i want!

Women...

Participant 16 appeared to be reporting internal voices resulting in continuous pessimism. He reported that these voices mentioned: 'Forget it! Why don't you abandon it? They don't want you! My self-esteem hides a lot of vulnerabilities. You will not manage in life! My tranquility hides a storm! My sense of power is an illusion! You 
spend your vital oxygen and your time is running out! What is the reason to exist? You can't day dream all the time!'

Health related problems were mentioned by three participants. Health problems were referred to as a struggle and the medication process as an unwanted procedure. For example, Participant 8 reported: 'I have drawn a person with an inhaler. I use an inhaler and it's something I don't like.'

Participant 5 mentioned a difficult condition with his brother which had been a cause of anxiety: 'what is happening with my brother, I worry that he might die.'

a) Socio-ecological factors

Ten participants (five from Greece and five from England) mentioned difficulties they were facing with family and peers.

Participant 1 mentioned: 'The mum or dad is walking out of the door. I have also put someone dying and children laying flowers at the grave. On the other side I've put how to deal with that - friends playing football' indicating the protective factors he perceived were a buffer against adversity.

Participant 5 mentioned: 'in my drawing I have written that friends can sometimes make life difficult. Bullies killing you and death are also hard because people are saints', demonstrating the context-specific nature of protective and risk factors. In this example, peer relationships, commonly referred to as a protective mechanism, could also be a risk factor.

Participant 10 explained how he was facing the negative comments of his peers and gave advice for how to manage this difficult situation:

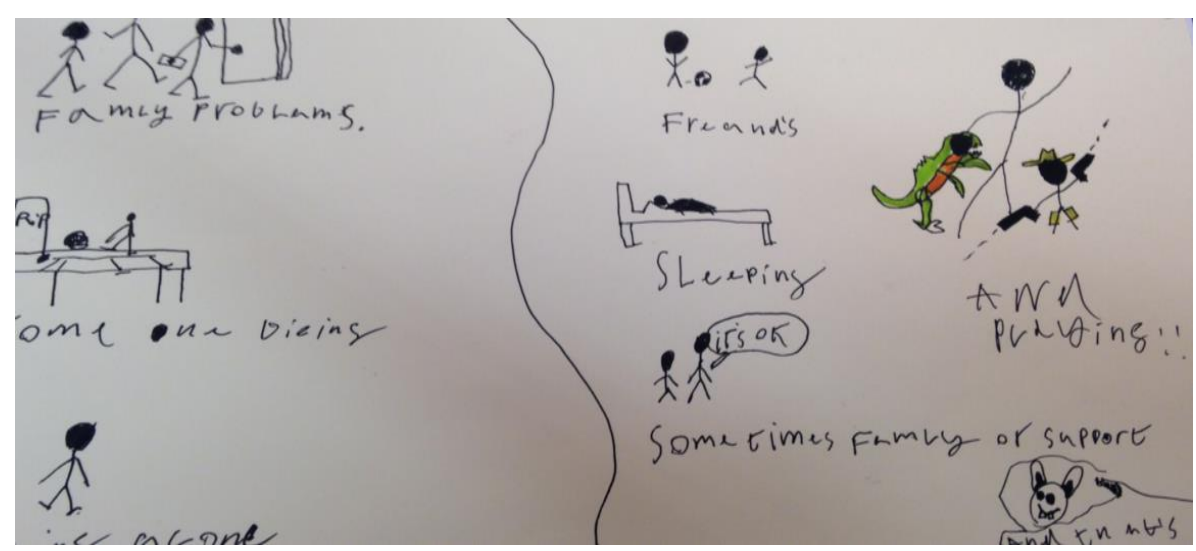

Figure 8. Drawing and accompanying words of Participant 9.

'In the difficulties there are family problems. The mum or dad is walking out of the door. I have also put someone dying and children laying flowers at the grave. On the other side I've put how to deal with that - friends playing football, playing with toys (dinosaur and cowboy), sleeping and sometimes family or friends to support you.... sometimes you can't do that if they are part of the problem.' 


\section{Discussion}

This study, based on the narratives and drawings of adolescents with complex needs, aimed to articulate the notion of resilience from the perspective of Greek and English young people with a range of emotional, behavioral and learning needs. The 'Draw and Write' technique has been previously applied by other researchers (Grove et al., 2018; McWhirter, 2014; Noonan et al., 2016; Pinquart, 2019 ) in a variety of situations. As in previous research, this study demonstrated the 'Draw and Write' technique as an effective data collection tool to explore the views and perspectives of children and young people with additional needs.

Emergent themes fell into the categories of risk and protective factors, at both personal and socio-ecological levels, that influence the resilience of adolescents who face a variety of emotional, behavioral and learning difficulties. Similar findings with children/adolescents with adversities or disabilities have been reported by Ogina (2012) and Lyons and Roulstone (2018).

A significant number of adolescents in our research mentioned positive thoughts and a sense of hope as a pathway to greater resilient. This finding is consistent with previous research that recognises hope as an important resilience factor for young people more generally ( $\mathrm{Li}$, Bottrell \& Armstrong, 2018; Masten, 2018; Pienaar et al., 2011; Pretorius, 2018).

The supportive role of teachers as a significant resilience factor was mentioned by many of the participants in this study. This finding agrees with the findings of several related studies with young people more broadly (Jefferis and Theron, 2017; Zolkoski and Bullock, 2012) indicating that teachers can facilitate resilience as key social-ecological stakeholders when they give guidance, inspire hope for the future and establish good relationships/partnerships with their students.

This study also provides crucial information about the important role of parents, not only to protect disabled adolescents from stress and adversities, but also in promoting the well-being of the whole family system (Masten, 2018). As such, it adds to other studies that have demonstrated the crucial role of adult caregivers in relation to young people more broadly (Dauenhauer et al., 2010). Children and adolescents living with families in adverse conditions often have far fewer resources and access to services which could help them to deal with their vital needs. Daily financial stress affects their lives and those families are more likely to experience poor health, low education, partnership conflicts, violence and low performance at school (Abelev, 2009). In addition, social isolation from the larger community often leads to children and adolescents being marginalised from large-scale resources, social stimuli and good quality health care.

As Masten (2018) mentions, the latest studies on intervention models to promote resilience in children and families are now focusing on positive goals, resources, processes and outcomes and shifting away from deficit-based models of treatment. Interventions strategies are now focusing on mitigating adversity (e.g. a parent's aggression), enhancing resources (e.g., health resources) and facilitating protective resources (e.g. improved family relationships) (Zolkoski \& Bullock, 2012).

This study provides various data extracted from adolescents' drawings and 
narratives which emerge from the diverse experiences and multiple realities of adolescents living with a disability/complex needs. Emerging realities clarified risk and protective factors and facilitated an understanding of how resilience is formed in these adolescents. Echoing previous findings related to young people with complex needs (Curtin et al., 2016), this study reveals a lack of material and psychological support for children and adolescents who experience a form of disability. Although some of the adolescents in our research reported material support from their families and relatives, there was a significant lack of engagement in loving, caring and emotional bonding relationships between them and the significant others in their lives. Our findings are supported by another similar study (Pienaar et al., 2011) which reported isolation and several emotional problems in addition to economic difficulties.

Our research promoted the emergence of adolescents' narratives through their drawings in relation to their emotional needs and their relationships with significant others. It was found that adolescents emphasised their loving and caring relationships with their families, peers, teachers and others as well as the positive characteristics of their socialisation through their skills, objects, places, activities, future expectations and problem solving as protective factors. This research also found an emphasis placed on positive relationships as a significant protective factor by adolescents with complex needs. More specifically having loving, caring and supportive relationships was reflected as a major 'weapon' of adolescents living with complex needs which helped them to stay on the surface of functional living. Our research concurs with previous researchers working with typically developing adolescents ( $\mathrm{Li}$ et al., 2018) in that adolescents can use their individual as well their socio-ecological resources as vital components to build their pathway to resilience. Many of our study's adolescents made use of personal coping mechanisms in the face of adversities; these were often linked to their own emerging optimism regarding their future life, positive thoughts and feelings as motivation as well as reminding themselves about all the people who stand on their side. Our research also concurs with previous studies (Masten \& Barnes, 2018) which have emphasised the role of functional attachment-relationships as a vehicle which helps to defend against adversities and buffer risk factors. The participants in this study differed from typically developing adolescents in terms of their views on how they formed the construct of resilience, not only because of their complex needs but also because of their concerns about potential social marginalisation (Lyons \& Roulstone, 2018).

This study used drawings as a tool and a specific form of visual method to facilitate and explore the experiences of adolescents living with complex needs in order to reflect on their self-perceptions of the notion of resilience and to describe their own problem solving in the context of their vulnerable circumstances.

Facilitated through a drawing technique, adolescents revealed their lack of emotional support from family and peers, which emerged as a major risk factor. On the other hand, empowering relationships with significant people like parents, brothers, friends, classmates, teachers were identified as protective factors that offered fundamental material and emotional needs and benefits. The current study emphasises the vital need for positive relationships as a defense in the lives of adolescents who feel emotionally deprived and lonely. Such relationships could derive from family context, educational environment as well as friends and 
peers in school and they potentially trigger all short of beneficial resources at an individual emotional level. As Li et al. (2018) state, parents in Western societies play an important role in helping their children to develop resilience with the support they provide at practical and emotional levels. Important others, such as teachers, seem to play a crucial role too, because it appears that they have a positive effect on academic achievement and on the development of positive behaviors ( $\mathrm{Li}$ et al., 2018). However, drawings and narratives of adolescents revealed diverse experiences and different experiences of vulnerability. We can identify an emerging repeating pattern/theme reflecting a transformation in the thinking of adolescents and the forming of a new identity in terms of future problem solving and a new vision from a position of vulnerability to a more optimistic vision of the future. Our argument is that in order for adolescents to find the resources they need and become more resilient, they have to adopt both new and different socialisation strategies, as well as motivating themselves and making use of their inner potential and all their dynamic personal traits, as new patterns to compensate for the absence of emotional and material needs, taking into account the dangers of utilising 'resilience' as a vehicle for the responsibilitasion of individuals in place of social structures and governing institutions (Hart et al., 2016).

\subsection{Cultural Considerations}

During adolescent development, it is normal for youths to face risks and negative life experiences at different points in time. Research suggests that environmental variables in an adolescent's ecology play an important part in their mental health outcomes and that the cumulative effect of multiple risk factors is associated with adolescent development (Hart et al., 2016).

The results of our research indicated that, irrelevant of gender, age, cultural and social status, all adolescents, both in Greece and England, perceived some common themes and patterns in terms of protective factors. However, the extent to which protective factors were effective in overcoming adversities and building resilience varied according to the current resources available to them in terms of loving and caring relationships and supportive adults, who facilitated the transformation from vulnerability to a more dynamic problem solving and positive perception of their future.

Adolescents who experienced a lack of social support systems were more likely to refer to places, pets and objects as protective factors, whereas those who lived in a more supportive environment described a more connected form of resilience (e.g. socio-ecological factors) in which the external environment facilitated a positive personal outlook and perspective. Future research should explore and clarify the nature of the resilience which is being fostered both in terms of selfprotective forms as well as more connected forms.

The above results suggest that any group of adolescents and any adolescent at an individual level is capable of developing mechanisms of resilience, regardless of their adversities and a lack of support from their social systems, even those who live with severe adversities and disabilities compared to adolescents who live in wealthier and better resourced communities. Adolescents with the highest levels of resilience protective factors are able to invest a large amount of psychological 
effort in their development (Van Breda, 2017) offering them an optimistic perspective of their future life.

From a global perspective, it is an important to note that feelings of anger, hopelessness and loneliness are an adolescent phenomenon. Yet, in this study, however poor an individual's resources were, there was an emerging sense of an interpersonal community from families and friends present in the lives of the adolescents, which acted as a major self-defense network in terms of adversities. Given the importance of cultural influences and their impact on the resilience development process, resilience can have a major role as long as parents, carers, teachers and other supportive adults communicate and manage stressful situations and adversities according to the cultural context. Our research findings emphasise the protective role of parents and peers, and are best understood as a form of dynamic interplay between risk and protective factors within a microcommunity of parents and peers. Our study concurs with previous research (Ilias et al., 2019) that argued that the process of resilience requires the functioning of many interacting systems within and around the parents and the micro-ecological environment, which operate at different levels.

Risk factors at the socio-ecological level, like poverty, emotional isolation, and family instability, do share clear commonalities both in Greece and England, as reflected in the drawings and narratives of the adolescent participants in this study. Similarly, personal qualities such as a positive attitude towards the future, and an ability to persevere seem to have a positive relationship with managing negative thoughts, health issues and other vulnerable situations in adolescents' lives. The above factors consist of dynamic interplay which have significant implications for working with youth who face complex needs and/or have disabilities. Understanding these factors, we attempted to identify implications for future practice.

It is a common truth that cultural variations play an important role in every aspect of the resilience process, since cultural issues can affect family and school practices in terms of building resilience in order to form expectations of adolescent behaviour which fit 'into their culture, community, or society' (Masten \& Barnes, 2018, p. 6).

\subsection{Implications for Practice}

Our key research findings regarding the perception of resilience could have significant implications for interventions for adolescents with complex needs and seem to be crucial in order to facilitate their transition to adulthood. A multilevel approach which focuses on the developmental stage of the adolescents in order to enhance their resilience should include 'assets and resources as the center for change' (Zolkoski \& Bullock 2012, p. 2300). According to these authors, to help adolescents with disabilities overcome barriers to a successful transition to adulthood, intervention programmes should focus on the: a) individual level (social skills, self-efficacy etc.); b) family level (e.g. family cohesion); and c) social environment (e.g. supportive teachers, relationships with peers) (Zolkoski \& Bullock, 2012). To add to these dimensions, and more controversially, it is also important to consider supporting children and young people to advocate for themselves for social change and to take part in activist activities that challenge 
their adversity contexts. This has the potential to be resilience building and is in line with the definition of resilience proposed in the 'Beating the odds and changing the odds' concept of 'Boingboing resilience' (Hart et al., 2016).

Ecological factors could offer resources and potential development to reassure individuals not only in terms of personal safety but also social growth. Social/ecological factors play a major role in the establishment of emerging resilience to sustain personality development. This is a significant research finding for schools and social welfare institutions providing vital care and resources to children and adolescents, emphasising that positive and enabling relationships, which constitute the fundamental ground of the ecological context, can be created and cultivated even in the most adverse and deprived communities (Zolkoski \& Bullock, 2012).

Building on the principles and practices of the Academic Resilience Approach that we explored in the first part of this article, school personnel should encourage and nurture relationships with children and adolescents, modelling healthy social skills for mature patterns of living. This will enable the internal and external space to be secured for children to feel valued and understood and to promote their welfare, creating bridges and connected communities of social support for the most disadvantaged individuals (Callaghan, Fellin \& Alexander, 2019; Hart \& Williams, 2015). Individual mentors could connect individuals with a whole community of external supporters as well as with family members. A community around the child should be created to meet their needs, so these supportive relationships can extend beyond immediate family and school staff. Building a connected community of relationships can begin to take place even in the playground and does not always require specific funding or any infrastructure.

Schools could become the shelters where families could absorb the necessary support, so as to function appropriately, and could be available for families in need, by offering human resources and social skills through parents' groups. In line with the UK's Future in Mind approach and Greece's (Law 3699/2008) school mental health practitioners and social workers could work more closely with families (Future in Mind, 2012). In particular, in Greece since 2013 (Law, $4115 / 2013$ ) school psychologists and social workers have been providing support to public schools for all vulnerable students who need it. Hence, their bond could become more intimate in the context of a local community and their role become more meaningful and influential in establishing a resilience framework adopting a symbolic, beneficial parental role. Promoting children's and adolescents' resilience could be the productive valuable outcome of that intense bond between all working parties in the residential settings of connected communities.

Our research findings also imply that qualified practitioners could be given more training on the fundamental concepts of resilience, including those which challenge notions of responsibilising individuals. This would help ensure that they are in a position to promote effective individual health and social human development and benefit, tackling all risk factors and creating protective resources. Our ethical responsibility is to create 'resilience-informed care' and practice so we can create and utilise strengths-based models and interventions (Patrick \& Wyckoff, 2018). Continuing personal and professional development for school personnel is vital. This would support their own resilience to provide 
better services and for many of them, change their focus from a 'deficit' model to a positive health development one (Masten and Barnes, 2018).

Going forward, a transdisciplinary, inter-professional framework is needed to mitigate risk and promote resilience in adolescents (Yu et al., 2018). Young people's views, and indeed leadership in creating it, should be central to this framework to maximise its efficacy and relevance. A 'test and learn' experiment in this regard relating to the application of Hart et al.'s Resilient Therapy approach is underway across a whole town in Blackpool, UK (www.boingboing.org.uk/reflections-big-resilience-together-blackpool/). It has become known as the first pilot for a 'Resilience Revolution'. Here, the 'transdisciplinary' approach goes beyond aspiring towards interprofessionalism. Rather, a community development approach is being instigated involving everyone in the town who wants to participate as a co-leader, whether a young person, parent, carer, policy maker or practitioner. Effective preparation, practice, and policy for resilience requires collaboration and coordination across systems, with strategic consideration of the best targets, timing, and alignment of interventions. Many systems contribute to resilience as children and adolescents develop, and in turn, they enhance the future resilience of their communities and societies (Masten \& Barnes, 2018).

\subsection{Limitations and Future Research}

The small sample size presents a major barrier to generalising the results of the present study, and these research findings could rather be seen as tendencies. Furthermore, the research was conducted in just two schools (one in Greece and one in the UK) and therefore the results may not be representative of all students with complex needs in Greece and the UK. Nonetheless, the findings of this study remain a useful tool for explicating the phenomenological experiences of resilience among adolescents with a variety of difficulties.

It is hoped that the results of the current research could contribute to the literature providing valuable material to better inform special education professionals on how to work more effectively with this population. Emergent research calls for a greater emphasis on challenging conditions of adversity by increasing the participation of marginalised groups as a way of overcoming disadvantage and contributing to social change (Ungar, 2005). This assertion is just as pertinent for school staff.

Future resilience research is required to clarify and explore more deeply the presence and the role of protective and beneficial relationships in managing, against the odds, vital emotional and material needs for the most disadvantaged children and young people, especially those who have complex needs. In addition, future research, of the nature conducted in this study, should include parents' and teachers' views on resilience in order to allow for triangulation of the data and produce more holistic results. It could also help in a comparison of adolescents', their parents' and teachers' perceptions both in Greece and the UK. Drawing has been revealed in this study as a useful tool for phenomenological enquiry and therefore future research could include that research tool to enhance the research perspectives. 


\section{Conclusion}

The current study highlights the importance of integrating the voices of children and adolescents with complex needs, so that it is possible to identify, from their own perspectives, potential risk factors for their well-being but also protective factors that can help them be more resilient. In that way, we can promote and apply protective strategies not only at an individual level but also in an environmental context (family, school, community) in order to enhance the wellbeing of individuals and help them to achieve academic success.

It is very important to identify the unique individual resilience characteristics and profile of each child and adolescent, as well his/her social/ecological and cultural environment. This enables a search for emerging risks and protective factors since the ways in which the identified themes manifest will be culturally and contextually specific. School-based psychoeducation programmes and therapeutic interventions could stimulate appropriate and developing skills to equip children and young people with the necessary social skills and problemsolving capabilities to tackle life's challenges and adversities on behalf of themselves and, potentially, on behalf of their peers. This would support the transformation from a passive situation to more active and independent living (van Breda, 2017).

Acknowledgments. The research in this paper was produced as part of the work undertaken through the successful Economic and Social Research Council funded Imagine programme (Grant Number ES/K002686/1 and ES/K002686/2) and subsequent 2015/2016 funded Designing Resilience activities. Thanks are due to all the co-researchers and participants involved in that study including academics, parents, carers, service users, practitioners and young people.

Contributions. MG, SP designed and conducted the study in Greece, wrote the manuscript, developed and performed the analysis. JM conducted the study in UK and edited the manuscript. EK \& AH reviewed and edited the manuscript and approved the final version of the manuscript.

Conflict of Interest. The authors declare that the research was conducted in the absence of any commercial or financial relationships that could be construed as a potential conflict of interest.

Funding. The present study was funded as part of the work undertaken through the successful Economic and Social Research Council funded Imagine programme (Grant Number ES/K002686/1 and ES/K002686/2) and subsequent 2015/2016 funded Designing Resilience activities.

Ethics Statement. Ethical approval was granted by the University of Crete and University of Brighton. Imagine was a five year Economic and Social Research Council (ESRC) project funded through the Research Councils UK Connected Communities programme. It ran from 2013-2017. Written informed consent was obtained from parents of participating adolescents and children. All parents of participants gave written informed consent in accordance with the Declaration of Helsinki. 


\section{References}

Abelev, M. S. (2009). Advancing out of poverty: Social class worldview and its relation to resilience. Journal of Adolescent Research, 24, 114-141. https://doi.org/10.1177/0743558408328441

Akos, P., \& Galassi, J. P. (2008). Strengths-based school counseling: Introduction to the special issue. Professional School Counseling, 12(2), 66-67. https:// doi.org/10.1177/2156759X0801200201

Benard, B. (1991). Fostering resiliency in kids: Protective factors in the family, school, and community.Washington: Western Center for Drug -Free School and Communities.

Callaghan, J. E. M., Fellin, L. C., \& Alexander, J. H. (2019). Promoting Resilience and Agency in Children and Young People Who Have Experienced Domestic Violence and Abuse: the "MPOWER" Intervention. Journal of Family Violence, 34(6), 521-537. https:// doi.org/10.1007/s10896-018-0025-x

Campbell, C., Skovdal, M., Mupambireyi, Z., \& Gregson, S. (2010). Exploring children's stigmatisation of AIDS-affected children in Zimbabwe through drawings and stories. Social Science and Medicine, 71(5), 975-985. https://doi.org/10.1016/j.socscimed.2010.05.028

Cameron, J., Wenger-Trayner, B., Wenger-Trayner, E., Hart, A., Buttery, L., Kourkoutas, E., Erygit-Madzawamuse, S., \& Rathbone, A. (2019). Community-university partnership research retreats: A productive force for developing communities of research practice. In S. Banks, A. Hart., K. Pahl, \& P. Ward (Eds.) Co-producing research: a community development approach. Bristol: Policy Press.

Dasarraju, R. K., Nirmala, S. V. S. G., Kolli, N. K. R., Inthihas, S., \& Nuvvula, S. (2016). Application of write-and-draw technique in pediatric dentistry: A pilot study. International Journal of Pedodontic Rehabilitation 1(2), 56. https://doi.org/10.4103/2468-8932.196482

Dauenhauer, J. A., Steitz, D. W., Aponte, C. I., \& Fromm Faria, D. (2010). Enhancing Student Gerocompetencies: Evaluation of an Intergenerational Service Learning Course, Journal of Gerontological Social Work, 53(4), 319-335. https://doi.org/10.1080/01634371003715577

Department for Education. (2017). Statutory Framework for the Early Years Foundation Stage. Available at: https://www.gov.uk/government/publications/early-yearsfoundation-stage-framework--2DfES/0672/2003. Retrieved from http://www.dfes.gov.uk/everychildmatters.

Creswell, J. (2014). Research Design: Qualitative, Quantitative, and Mixed Methods Approaches. Thousand Oaks, California: SAGE Publications.

Curtin, K. A., Schweitzer, A., Tuxbury, K., \& D'Aoust, J. A. (2016). Investigating the Factors of Resiliency among Exceptional Youth Living in Rural Underserved Communities. Rural Special Education Quarterly, 35(2), 3-9. https://doi.org/10.1177/875687051603500202

Farmer, S., \& Porcellato, L. (2016). "Thinking about drinking": Exploring children's perceptions of alcohol using the Draw and Write tool. Health Education, 116(6), 541-560. https://doi.org/10.1108/HE-08-2015-0024

Future in Mind. (2012). "Promoting, protecting and improving our children and young people's mental health and wellbeing." UK: NHS.

Grove, L., Morrison-Beedy, D., Kirby, R., \& Hess, J. (2018). The Birds, Bees, and Special Needs: Making Evidence-Based Sex Education Accessible for Adolescents with Intellectual Disabilities. Sexuality and Disability, 36(4), 313-329. https://doi.org/10.1007/s11195-018-9547-7

Harðardóttir, S., Júlíusdóttir, S., \& Guðmundsson, H. S. (2015). Understanding Resilience in Learning Difficulties: Unheard Voices of Secondary School Students. Child and 
Adolescent Social Work Journal, 32(4), 351-358. https://doi.org/10.1007/s10560014-0373-1

Hart, A., Blincow, D., \& Thomas, H. (2007). Resilient Therapy. Hove: Routledge.

Hart, A., Gagnon, E., Eryigit-Madzwamuse, S., Cameron, J., Aranda, K., Rathbone, A., \& Heaver, B. (2016). Uniting Resilience Research and Practice With an Inequalities Approach. SAGE Open. https://doi.org/10.1177/2158244016682477

Hart, A., \& Williams, L. (2015) The Academic Resilience Approach. https://www.boingboing.org.uk/academic-resilience-approach/.

Henry, C. S., Morris, A. S., \& Harrist, A. W. (2015). Family resilience: Moving into the third wave.Family Relations, 64(1), 22-43. https://doi.org/10.1111/fare.12106

Ilias, K., Cornish, K., Park, M. S. A., Toran, H., \& Golden, K. J. (2019). Risk and resilience among mothers and fathers of primary school age children with ASD in Malaysia: A qualitative constructive grounded theory approach. Frontiers in Psychology, (JAN), 1-20. https:// doi.org/10.3389/fpsyg.2018.02275

Jefferis, T. C., \& Theron, L. C. (2017). Promoting resilience among sesotho-speaking adolescent girls: Lessons for south African teachers. South African Journal of Education, 37(3), 1-11. https:// doi.org/10.15700/saje.v37n3a1391

Jönsson, A. (2018). Meeting the Needs of Low-Achieving Students in Sweden: An Interview Study. Frontiers in Education, 3, 1-16. https:// doi.org/10.3389/feduc.2018.00063

Kim, J. (2016). Narrative data analysis and interpretation. In J. Kim (Ed.) Understanding narrative inquiry (pp. 184-225). SAGE Publications, Inc. https://doi.org/10.4135/978107180286

Khair, K., Meerabeau, L., \& Gibson, F. (2015). Self-management and skills acquisition in boys with haemophilia. Health Expectations, 18(5), 1105-1113. https://doi.org/10.1111/hex.12083.

Kuhn, P. (2003). Thematic Drawing and Focused, Episodic Interview upon the Drawing A Method in Order to Approach to the Children's Point of View on Movement, Play and Sports at School. Forum Qualitative Social Research,4 (1). https://doi.org/10.17169/fqs-4.1.750

Law 3699/2008 (Government Gazette 199/issue A'/2-10-2008): 'Special Education and Training of persons with disabilities or with special educational needs'.

Law 4115/2013. Providing for the Organisation and Function of the Institute of Youth and Lifelong Learning and of the National Organisation for the Certification of Qualifications and Career Guidance, and other provisions.

Lerner, R. M., Agans, J. P., Arbeit, M. R., Chase, P. A., Weiner, M. B., Schmid, K. L., \& Warren, A. (2013). Resilience and positive youth development: A relational developmental systems model. In n Goldstein, S., Brooks, R. B. (Eds.) Handbook of resilience in children ( $2^{\text {nd }}$ ed., pp. 293-308). NY: Springer.

Li, H., Bottrell, D., \& Armstrong, D. (2018). Understanding the Pathways to Resilience: Voices from Chinese Adolescents. Young, 26(2), 126-144. https://doi.org/10.1177/1103308817711532

Lichtman, M. (2006). Qualitative research in education, a user's guide. Thousand Oaks: Sage

Luthar, S. S., Cicchetti D., \& Becker, B. (2000). The construct of resilience: a critical evaluation and guidelines for future work. Child Dev., 71(3), 543-562. https://doi.org/10.1111/1467-8624.00164

Lyons, R., \& Roulstone, S. (2018). Well-Being and Resilience in Children With Speech and Language Disorders. Journal of Speech Language and Hearing Research, 61(2), 324. https://doi.org/10.1044/2017_JSLHR-L-16-0391 
Masten, A. S. (2018). Resilience Theory and Research on Children and Families: Past, Present, and Promise. Journal of Family Theory \& Review, 10(1), 12-31. https://doi.org/10.1111/jftr.12255

Masten, A. S., \& Barnes, A. J. (2018). Children Commentary Resilience in Children: Developmental Perspectives. https://doi.org/10.3390/children5070098

Masten, A. S., \& Obradovic, J. (2008). Disaster preparation and recovery: Lessons from research on resilience in human development. Ecology and society 13(1), 1-9. https:// doi.org/10.5751/ES-02282-130109

McWhirter, J. (2014). The Draw and Write Technique as a Versatile Tool for Researching Children's Understanding of Health and Well-Being. International Journal of Health Promotion and Education 52(5), 250-59. https://doi.org/10.1080/14635240.2014.912123

Moreno, J., Sanabria, L., \& López, O. (2016) Theoretical and Conceptual Approaches to Co-Regulation: A Theoretical Review. Psychology, 7, 1587-1607. https://doi.org/10.4236/psych.2016.713153

Noonan, R. J., Boddy, L. M., Fairclough, S. J., \& Knowles, Z. R. (2016). Write, Draw, Show, and Tell: A Child-Centred Dual Methodology to Explore Perceptions of out-ofSchool Physical Activity. BMC Public Health, 16(1), 1-19. https:// doi.org/10.1186/s12889-016-3005-1

Ogina, T. A. (2012). The use of drawings to facilitate interviews with orphaned children in Mpumalanga province, South Africa. South African Journal of Education, 32(4), 428440. https://doi.org/10.1177/0743558415600072

Olsson, L., Jerneck, A., Thoren, H., Persson, J., \& O'Byrne, D. (2015). Why resilience is unappealing to social science: Theoretical and empirical investigations of the scientific use of resilience. Science Advances, 1(4). https://doi.org/10.1126/sciadv.1400217

Palikara, O., Castro, S., Gaona, C., \& Eirinaki, V. (2018). Capturing the Voices of Children in the Education Health and Care Plans: Are We There Yet? Frontiers in Education, 3(April), 1-9. https://doi.org/10.3389/feduc.2018.00024

Patrick, K. A., \& Wyckoff, L. (2018). Providing Standards for Diabetes Care in the School Setting: A Review of the Colorado Model. NASN School Nurse (Print), 33(1), 52-56. https://doi.org/10.1177/1942602X17725886

Petty, N. J., Thomson, O. P., \& Stew, G. (2012). Ready for a paradigm shift? Part 2: Introducing qualitative research methodologies and methods. Manual Therapy, 17(5), 378-384. https://doi.org/10.1016/j.math.2012.03.004

Pienaar, A., Swanepoel, Z., Van Rensburg, H., \& Heunis, C. (2011). A qualitative exploration of resilience in pre-adolescent AIDS orphans living in a residential care facility. Journal of Social Aspects of HIV/AIDS, 8 (3), 128-137. https:// doi.org/ 10.1080/17290376.2011.9724995

Pinquart, M. (2019). Featured article: Depressive symptoms in parents of children with chronic health conditions: A meta-analysis. Journal of Pediatric Psychology, 44(2), 139-149. https://doi.org/10.1093/jpepsy/jsy075

Pretorius, W. (2018). Hope as pathway for resilience in South African youth. Doctoral dissertation, University of Pretoria.

Pridmore, P., \& Bendelow, G. (1995). Images of health: Exploring beliefs of children using the 'draw-and-write' technique. Health Education Journal, 54(4), 473-488. https://doi.org/10.1177/001789699505400410

Riley, J. R., \& Masten, A. S. (2005). Resilience in context: Linking context to practice and policy. In R. D. Peters, B. Leadbeater, \& R. J. McMahon (Eds.), Resilience in children, families, and communities: Linking context to practice and policy (pp. 13-25). Kluwer Academic/Plenum. 
Seligman, M. E., \& Csikszentmihalyi, M. (2014). Positive psychology: An introduction. In Flow and the foundations of positive psychology (pp. 279-298). Springer, Dordrecht. https:// doi.org/10.1007/978-94-017-9088-8

Smith, L., Foley, P. F., \& Chaney, M. P. (2008). Heterosexism in Counselor Education. Journal of Counseling and Development, 86(3), 303-310. Retrieved from http:/ / aca.metapress.com/index/R75T7GN665243268.pdf

Soderberg, A. M. (2006). Narrative interviewing and narrative analysis in a study of a cross-border merger. Management International Review, 46 (4), 397-416. https://doi.org/10.1007/s11575-006-0098-2

Theron, L. C. (2016). Toward a Culturally and Contextually Sensitive Understanding of Resilience: Privileging the Voices of Black, South African Young People. Journal of Adolescent Research 31(6), 635-70. https:/ / doi.org/10.1177/0743558415600072

Ungar, M.(2005). Handbook for working with children and youth: Pathways to resilience across cultures and contexts. Thousand Oaks: Sage.

van Breda, A. D. (2017). A comparison of youth resilience across seven South African sites. Child and Family Social Work, 22(1), 226-235. https://doi.org/10.1111/cfs.12222

Werner, E. E., \& Smith R. S. (1992). Overcoming the Odds: High Risk Children from Birth to Adulthood. NY: Cornell University Press.

Yoshikawa, H., Aber, J. L.,\& Beardslee, W. R. (2012). The effects of poverty on the mental, emotional, and behavioral health of children and youth: implications for prevention. American Psychologist, 67(4), 272. https://doi.org/10.1037/a0028015

Yu, X., Zuk, J., \& Gaab, N. (2018). What Factors Facilitate Resilience in Developmental Dyslexia? Examining Protective and Compensatory Mechanisms Across the Neurodevelopmental Trajectory. Child Development Perspectives, 12(4), 240-246. https://doi.org/10.1111/cdep.12293

Zolkoski, S. M., \& Bullock, L. M. (2012). Resilience in children and youth: A review. Children and Youth Services. Review, 34(12), 2295-2303. https://doi.org/10.1016/j.childyouth.2012.08.009

\section{Appendix 1}

\section{INTERVIEW PROMPT QUESTIONS}

1. Can you please draw a child like yourself?

2. What do you think this child is thinking about himself and his future?

3. When this child is facing difficulties in his life, what helps him/her to overcome these difficulties?

4. What helps him/her to find courage in his life?

5. Draw and write. (If you need help, I can write for you.) 